\title{
Pre-breeding for waxy proso millet by phenotyping and marker-assisted selection
}

\author{
Irina Zhirnova ${ }^{1}$, Aiman Rysbekova $^{1 *}$, Elmira Dyussibayeva ${ }^{1}$, Aiym Zhakenova ${ }^{1}$, \\ Bekzak Amantaev ${ }^{1}$, Yin-Gang $\mathrm{Hu}^{2}$, Bai-Li Feng ${ }^{2}$, and Zhazira Zhunusbayeva ${ }^{3}$
}

${ }^{1}$ S. Seifullin Kazakh AgroTechnical University, Agronomic Faculty, 010011, Nur-Sultan, Republic of Kazakhstan.
"Corresponding author (aiman_rb@ mail.ru).
2Northwest A\&F University, College of Agronomy, State Key Laboratory of Crop Stress Biology for Arid Areas, Yangling,
712100, Shaanxi, P.R. China.
${ }^{3}$ Al-Farabi Kazakh National University, Faculty of Biology and Biotechnology, 050040, Almaty, Republic of Kazakhstan.

Received: 27 February 2021; Accepted: 20 July 2021; doi:10.4067/S0718-58392021000400518

\begin{abstract}
Proso millet (Panicum miliaceum L.) is important in some Kazakhstan food, this research objective was to develop prebreeding waxy proso millet resource for breeding new varieties by using phenotyping and marker-assisted selection. The amylose content of the endosperm starch in a collection of 18 proso millet cultivars widely used in northern Kazakhstan were evaluated and ranged from $14.6 \%$ to $34.8 \%$. The introduced glutinous millet accessions of PI436626 (Lung Shu 18), PI436625 (Lung Shu 16) were selected to cross with local cultivars (Saratovskoe 6 and Pamyati Bersieva). The potassium iodide (KI) staining method and PCR analysis using the 9bF/15delRB primer were used to identify the waxy trait for selection of the $\mathrm{F}_{2}-\mathrm{F}_{3}$ generation. Seeds staining dark blue to black were scored as wild type, while waxy seeds were stained as pinkish or amber to reddish-brown color. The hybridological analysis of inheritance of the "waxy" trait suggested that the segregation ratios for waxy endosperm in the $F_{2}$ and $F_{3}$ populations was close to 15:1 of the caryopses with blue and brown colors. PCR analysis with the $9 \mathrm{bF} / 15$ delRB primer confirmed that this specific primer flanks a 123 bp fragment in amylose samples, while in glutinous samples, this primer promotes the amplification of 108 bp long PCR product (15 nucleotides deletion). Finally, the waxy lines were obtained and could be used for further testing.
\end{abstract}

Key words: Amylose content, glutinous variety, hybridization, Panicum miliaceum, proso millet, waxy gene.

\section{INTRODUCTION}

Common millet (Panicum miliaceum L.) is the oldest valuable cereal and forage crop in the world. Its cultivation began 10000 years ago in Northern China (Lu et al., 2009). Proso millet is a short day $\mathrm{C}_{4}$ plant and is one of the most valuable crops for universal use. The green pulp has a quality that can compete with the green pulp of maize, sorghum, and Sudan grass. Millet can rightfully be considered the main crop culture of ancient Europeans (Sidorenko et al., 2012). The appearance of millet in Canada dates back to the $17^{\text {th }}$ century (Baltensperger et al., 2002). In the modern world, millet is cultivated in Asia, Australia, North America, Europe, and Africa (Brink and Belay, 2006; Zhang et al., 2019). Asian countries use millet as a food crop; USA is actively engaged in its growing for livestock and poultry (Dikshit and Sivaraj, 2013; Santra and Rose, 2013).

World production of millet is at a fairly high level and occupies a significant place. According to FAO, the sown area of millet ranks sixth in terms of sown areas (34.7 million hectares) and gross grain harvest (31.6 million tons) among cereals, second only to wheat, rice, barley, corn, and sorghum. Millet is cultivated in 30 countries of the world, including 18 European countries. The main grain producers of this crop are Russia, India, USA, China and Ukraine (Zotikov et al., 2012). Due to its early maturity, drought resistance, productivity, and other valuable biological and economic characteristics, this crop can be widely used in production (Minina, 2014). 
In Kazakhstan, proso millet is one of major cereal crops distinguished by its high drought and salt tolerance as well as low response to sowing dates, which is especially important in the dry steppe zone (Tsygankov et al., 2004). In breeding of millet, cereal and forage directions are distinguished, as well as creation of special-purpose varieties, in particular, varieties with the starch consisting entirely of amylopectin. According to the qualitative composition of starch, cereals, including millet, are subdivided into waxy type, the starch of which is almost $100 \%$ amylopectin, and common (wild) millet, in which up to 30\% of starch is amylose (Sakamoto, 1987; Hunt et al., 2013). In high-amylose samples of millet, the amylose content ranges from $20 \%$ to $32 \%$ (Beleia et al., 1980; Kim et al., 2012), samples with an amylose content of 3.3\%-11.4\% belong to low-amylose varieties (Hoover et al., 1996; Kim et al., 2009).

It has been established that the common type of starch in proso millet is controlled by the dominant alleles of $W x$ gene, which encodes in cereals the synthesis of the enzyme associated with granule-bound starch synthase (GBSS), whereas the waxy type (amylopectin) by its recessive $w x$ alleles (Fukunaga et al., 2002; Araki et al., 2012). Since millet is a tetraploid plant, the genotype of different varieties may contain one $W x$ gene or two $(W x 1$ and $W x 2)$. If the endosperm of common millet varieties contains both types of starch molecules, it can be concluded that the dominant alleles of the $W x$ gene in such forms function only at a certain stage. Hunt et al. (2010) showed the presence of two different loci of these genes designated "L type" and "S type".

Waxy (glutinous) forms of proso millet (endosperm starch in which lacks amylose) have been known since the $19^{\text {th }}$ century (Hixon and Brimhall, 1968). Waxy proso millet obviously occurs widespread across Asia (Kimata and Negishi, 2002). A significant part of millet varieties cultivated in USA and European countries possesses the "wild" type of starch, presenting a mixture of amylose and amylopectin, while in Asian countries breeding programs aimed at creating varieties of the waxy type, in which content of amylose is insignificant (Graybosch and Baltensperger, 2009).

On the market today waxy types of proso millet are in high demand due to their increased stickiness and food value. Millet obtained from glutinous forms of millet is a valuable dietary product, which removes toxic compounds, toxins, and even heavy metal ions from the body. It should also be noted that millet is capable of removing antibiotics from the body (Kim et al., 2012).

The State Register of Breeding Achievements recommendation for use on the territory of the Republic of Kazakhstan includes 21 varieties of proso millet, there are no glutinous varieties among them. The price of glutinous millet on American and Asian markets is estimated at around $4 \mathrm{USD} \mathrm{kg}^{-1}$, while on the local market the price of ordinary millet is only $1 \mathrm{USD} \mathrm{kg}^{-1}$. The purposes of the present investigation were to identify waxy types of proso millet from the Kazakhstan collection based on biochemical and molecular analysis; evaluate the inheritance of the waxy trait after crossing with amylose (wild) type proso millet; and create pre-breeding sources of waxy proso millet for breeding new Kazakhstani varieties.

\section{MATERIALS AND METHODS}

\section{Breeding material}

Varieties and samples of proso millet (Panicum miliaceum L.) from local and world collection of various ecological and geographical origins were used as a starting material. The 18 Kazakhstan proso millet cultivars were bred in the last $40 \mathrm{yr}$. The low-amylose millet accessions of PI346946, PI436622 (Lung Shu 5), PI436623 (Lung Shu 7), PI436624 (Lung Shu 14), PI436625 (Lung Shu 16) and PI436626 (Lung Shu 18) were used as the waxy donors, which were obtained from the North Central Regional Plant Introduction Station (NCRPIS), Iowa State University, Ames, Iowa, USA.

The work was carried out in laboratory and field conditions. Laboratory studies were carried out at the Scientific Research Platform of Agricultural Biotechnology (RPAB) at the Saken Seifullin Kazakh Agrotechnical University, NurSultan, Republic of Kazakhstan. Field experiments were carried out from May to September in the 2019 and 2020 growing seasons in the breeding nursery of the Scientific Production Center of Grain Farming named A.I. Baraev (Shortandy village-1, Shortandy district, Akmola region, Republic of Kazakhstan) in the dry steppe zone of the Akmola region.

\section{Determination of total amylose content in millet grain by $\mathbf{I}_{2}$-KI}

Grain starch amylose concentrations were determined according to Singh and Adedeji (2016). Millet samples containing $100.0 \pm 0.1 \mathrm{mg} \mathrm{DM}$ were weighed and mixed with $1 \mathrm{~mL} 95 \%$ ethanol and $9 \mathrm{~mL} 1 \mathrm{~N}$ solution of $\mathrm{NaOH}$, transferred to 
$100 \mathrm{~mL}$ volumetric flasks. After being kept at room temperature for $10 \mathrm{~min}$, flasks were heated on a water bath at $100{ }^{\circ} \mathrm{C}$ for $10 \mathrm{~min}$, and left to cool at room temperature. The resulting mixture was diluted to $100 \mathrm{~mL}$ with $\mathrm{dH}_{2} \mathrm{O}$ and stirred. An

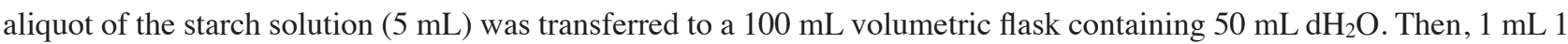
$\mathrm{N}$ solution of acetic acid and $2 \mathrm{~mL} 0.2 \%$ iodine solution $\left(\mathrm{I}_{2}-\mathrm{KI}\right)$ were added to the same flask; it was filled to a volume of $100 \mathrm{~mL}$ and left for $20 \mathrm{~min}$ at room temperature. Dark blue to black were scored as wild type, while waxy type was noted by their pinkish or amber to reddish-brown color. The optical density was measured on a spectrophotometer (PE-5400UV, Erkos, Moscow, Russia) at a wavelength of $620 \mathrm{~nm}$. The experiment was carried out in triplicate, results were processed statistically using the Microsoft Excel program.

\section{Genomic DNA extraction from millet seedlings}

For molecular genetic analysis, DNA was isolated from 7-d-old chlorophyll-free seedlings by the modified cetyl trimethylammonium bromide (CTAB) method (Murray and Thompson, 1980) as following: 100-200 mg seedlings were placed in a $2 \mathrm{~mL}$ test tube, where $400 \mu \mathrm{L}$ CTAB $2 \%$ extraction buffer was added, and gently grinded with a plastic rod; 10 $\mu \mathrm{L}$ RNase was subsequently added to the tube, with the latter incubated for $60 \mathrm{~min}$ at $65^{\circ} \mathrm{C}$ in a water bath, periodically shaken; $400 \mathrm{~mL}$ chloroform-isoamyl alcohol were added and centrifuged for $1 \mathrm{~min}$ at maximum speed (13000 rpm). The upper phase was carefully removed with a pipette, transferred to a new tube and $350 \mathrm{~mL}$ cold isopropanol was added and mixed thoroughly. It was centrifuged for $5 \mathrm{~min}$ at maximum speed (13000 rpm), the alcohol was discarded, and the DNA was left in an open tube for drying. Dried DNA was dissolved in distilled water, the concentration was determined using UV-Vis spectrophotometers (NanoDrop 2000, Thermo Fisher Scientific, Waltham, Massachusetts, USA).

\section{PCR analysis}

To identify the $W x$ gene, PCR was performed using the 9bF/15delRB primer, which amplified the region of Intron 9/Exon10, and detected the 15 bp deletion in wax type (Araki et al., 2012). The sequence (5-3') of 9bF/15delRB marker was as 9bF: CAAGGAAGCATTTCAGGCCATCGCT, and 15delRB: TGCTCCTCCAGCCTGCCGACA, which were synthesized by Applied Biosystems (Foster City, California, USA).

The PCR reaction mixture of $15 \mu \mathrm{L}$ contained: $8 \mu \mathrm{L}$ NZYTaq II $2 \times$ Green Master Mix (NZYTech, Lisboa, Portugal), $5.2 \mu \mathrm{L} \mathrm{ddH} \mathrm{H}_{2} \mathrm{O}, 1 \mu \mathrm{L} 10 \mu \mathrm{M}$ each primer (F, R) and 100-150 ng DNA template. The amplification was carried out in a thermal cycler (SimpliAmp, Thermo Fisher Scientific) under the following conditions: 4 min at $94{ }^{\circ} \mathrm{C}$; 35 cycles with $94{ }^{\circ} \mathrm{C} 1 \mathrm{~min}, 59^{\circ} \mathrm{C} 1 \mathrm{~min}, 72{ }^{\circ} \mathrm{C} 1 \mathrm{~min}$; further at $72{ }^{\circ} \mathrm{C} 8$ min. Products of PCR were separated using $1.5 \%$ agarose gel electrophoresis (molecular biology grade, Invitrogen, Waltham, Massachusetts, USA) in Tris-acetate-EDTA (TAE; Trisacetate $40 \mathrm{mM}$, EDTA $1 \mathrm{mM}, \mathrm{pH}$ 8.0), and 100 bp ladder (BioLabs, London, UK) was used as a marker of molecular weight. Electrophoresis was performed at a constant voltage of $120 \mathrm{~V}$ for $1 \mathrm{~h}$. After electrophoresis, the results of amplification were visualized using a gel documenting system (TCP-20.MC, Vilber Lourmat, Eberhardzell, Germany, 2010).

\section{Crosses and selection of low-amylose and waxy proso millet}

To obtain low-amylose pre-breeding materials, the world standards of glutinous accessions PI436626 and PI346946 were used as recipient forms, to cross with some Kazakhstan cultivars, as the pollen donors.

For hybridization, the parents were sown in vegetation vessels for three periods with an interval of $10 \mathrm{~d}$ to synchronize their flowering periods. Crosses were made at the beginning of the flowering stage, when the upper and middle parts of the panicle were blooming. Manual castration was carried out, 20-30 of the most developed spikelets were left on one panicle, the flower films were carefully opened, and anthers were removed with tweezers. A parchment insulator was put on the panicle. Pollination was carried out the next day by opening the flower and applying the paternal pollen to the stigma of the pistil. The combination scheme, date and time of pollination, number of plot and row number were stamped on the isolator. Upon full ripeness, the percentage of seed set was calculated by the number of formed grains and seeds were harvested.

Resulting hybrids and parents were manually planted in the field in a hybrid nursery, the area of the plot was $1 \mathrm{~m}^{2}$, the arrangement of the plots was systematic. The $F_{1}$ seeds were then harvested, and the $F_{2}$ populations were planted next year, seeds of each individual were harvested separately, then analyzed by potassium iodide (KI) staining method. The KI staining method was used to identify grains of waxy type millet, as the endosperm of glutinous types with the recessive 
$w x$ gene was colored brown, while that of the amylose types with the dominant $W x$ gene was colored blue. The phenotypic waxy endosperm is dense in consistency, but matte in color with a high content of dextrins, which impair the technological and culinary qualities of cereals (Dzyuba et al., 2015).

\section{RESULTS}

\section{Identification of the waxy gene in the millet varieties in Kazakhstan}

In creating glutinous forms, the content of amylose in the grains of millet varieties from Kazakhstan in the last 40 yr was estimated by biochemical screening (Table 1 ).

The results showed that there were great variations in amylose content among the examined varieties cultivated in Kazakhstan, which ranged in $14.6 \%$ 29.3\%. According to the classification, these varieties belong to the medium and high amylose groups, which suggested the absence of waxy samples of millet in Kazakhstani breeding.

As waxy proso millet has not been previously bred in Kazakhstan, there is no information on waxy genes of Kazakhstan varieties. The PCR identification of the allelic state of the waxy gene using the 9bF/15delRB marker showed that all the varieties in Kazakhstan were with the Wax loci, while the glutinous standards PI346946 from the USDA and MaZhaYan from Chinese collection were with the wax loci. PCR with marker 9bF/15delRB clearly amplified the 123 bp product typical for medium and high amylose varieties, as shown for the Kazakhstan varieties, while the 108 bp product for the glutinous variety. In this case, glutinous samples differ from amylose by 15 bp deletion in the $\mathrm{S}$ region of the Waxy gene locus.

\section{Segregation of waxy traits in the $\mathrm{F}_{2}-\mathrm{F}_{3}$ progeny}

Three crosses were carried out as PI436626×Saratovskoe 6 (P1), PI346946 with Pamyati Bersieva and Kokshetavskoe 66 (P2 and $\mathrm{P} 3$, respectively), the setting of hybrid seeds during manual castration ranged from $5.0 \%$ to $47.2 \%$. The resulting hybrid caryopses were sown in the field to produce the $F_{1}$ generations. After seed maturation, each hybrid combination was harvested separately and $F_{1}$ sterility was determined. In the field, a hybrid nursery of $F_{1}-F_{2}$ hybrids and their parental forms was established to select the promising low-amylose forms of millet from splitting $\mathrm{F}_{2}-\mathrm{F}_{3}$ populations. Each plant in $\mathrm{F}_{1}-\mathrm{F}_{2}$ generation was visually analyzed (Figure 1 ).

Table 1. Amylose content of proso millet varieties from Kazakhstan.

\begin{tabular}{|c|c|c|c|c|}
\hline Variety & Year of admission & Origin & Vegetation period & Amylose \\
\hline & & & $\mathrm{d}$ & $\%$ \\
\hline Saratovskoe 3 & 1981 & Russia & 79 & 25.7 \\
\hline Uralskoe 109 & 1981 & Kazakhstan & 89 & 28.9 \\
\hline Saratovskoe 6 & 1985 & Russia & 79 & 28.8 \\
\hline Shortandinskoe 7 & 1994 & Kazakhstan & 82 & 28.4 \\
\hline Omskoe 11 & 1994 & Russia & 79 & 24.8 \\
\hline Saratovskoe10 & 2006 & Russia & 80 & 26.5 \\
\hline Pamyati Bersieva & 2009 & Kazakhstan & 75 & 23.4 \\
\hline Shortandinskoe10 & 2009 & Kazakhstan & 82 & 29.3 \\
\hline Yarkoe 3 & 2009 & Kazakhstan & 83 & 25.5 \\
\hline Shortandinskoe11 & 2011 & Kazakhstan & 82 & 28.7 \\
\hline Pavlodarskoe & 2011 & Kazakhstan & 82 & 29.4 \\
\hline Yarkoe 5 & 2012 & Kazakhstan & 82 & 26.9 \\
\hline Barnaulskoe 98 & 2013 & Kazakhstan & 84 & 28.8 \\
\hline Yarkoe 7 & 2015 & Kazakhstan & 82 & 28.6 \\
\hline Yarkoe 6 & 2016 & Kazakhstan & 82 & 28.7 \\
\hline Yarkoe 120 & 2017 & Kazakhstan & 82 & 28.1 \\
\hline Pavlodarskoe 4 & 2017 & Kazakhstan & 82 & 20.1 \\
\hline Yarkoe ubileinoe & 2019 & Kazakhstan & 82 & 24.8 \\
\hline
\end{tabular}


Figure 1. Husk shape and color of obtained Panicum miliaceum $\mathrm{F}_{1}$ hybrids.
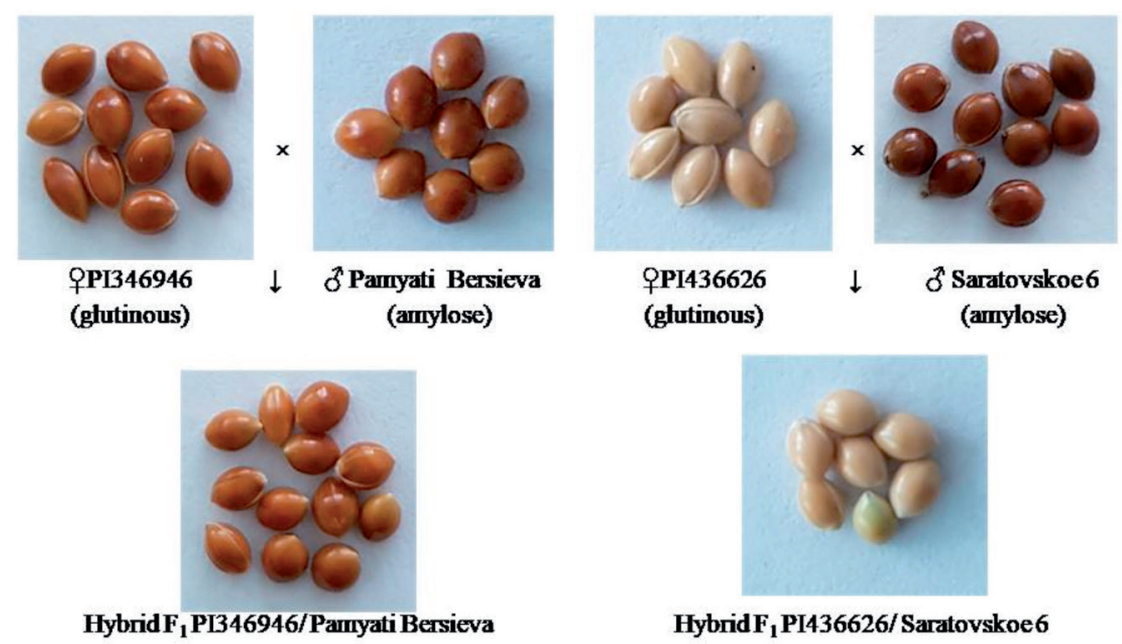

Hybrid F 1 PI346946/Pamyati Bersieva

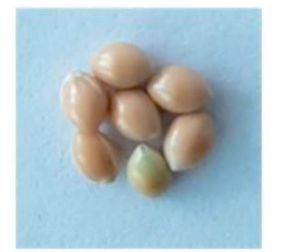

HybridF, PI436626/Saratovskoe6

Figure 1 clearly show that seeds of $F_{1}$ hybrids derived from PI436626×Saratovskoe 6 and PI346946×Pamyati Bersieva have the similar caryopsis color as the female parent, which suggested that color of the flower scales was inherited from the maternal form. These combinations were planted next year in the field conditions, and the $\mathrm{F}_{2}$ populations were harvested separately. To identify a waxy trait for selection by using $2 \%$ KI solution, a hybridological analysis was performed on the $\mathrm{F}_{2}-\mathrm{F}_{3}$ generation of the crosses of PI436626×Saratovskoe 6 and PI346946×Pamyati Bersieva. Seeds staining dark blue to black were scored as wild type, while waxy seeds were stained as pinkish or amber to reddishbrown color (Figure 2).

In $\mathrm{F}_{1}$ generation, all obtained hybrid caryopses were blue when stained with $2 \% \mathrm{KI}$, as domination of amylose endosperm, while the waxy parents were pinkish or amber to reddish-brown. Staining analysis in populations $\mathrm{F}_{2}-\mathrm{F}_{3}$ showed that the color of the endosperm was determined by their genotype, i.e., endosperm with a dominant $W x$ gene was colored blue, while endosperm with two recessive waxy genes was stained brown. Further we observed that the ratio of caryopses with blue and brown colors was close to $15: 1$, with $\chi^{2}$ in the range of $0.06-0.07$ at a probability between $0.90<\mathrm{P}<0.75$ (Table 2), which suggested that this trait was controlled by two dominant Waxy genes, and the staining the caryopses with 2\% KI solution can be a better way for assist the selection of wax proso millet in the breeding program.

Figure 2. Starch granules of Panicum miliaceum stained with $2 \%$ potassium iodide solution: wild type stained dark blue (a), and waxy type stained reddish-brown (b).

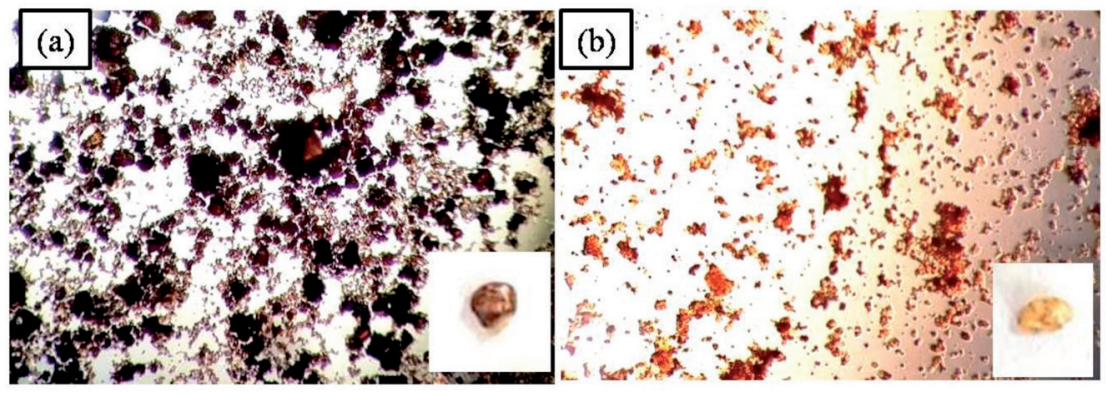

Table 2. Hybridological analysis of $F_{2}-F_{3}$ generations of hybrids by endosperm color.

\begin{tabular}{|c|c|c|c|c|c|c|}
\hline \multirow[b]{2}{*}{ Crossing combinations } & \multirow{2}{*}{$\begin{array}{l}\text { Endosperm } \\
\text { coloring }\end{array}$} & \multicolumn{3}{|c|}{ Number of tested grains } & \multirow[b]{2}{*}{$\chi^{2}$} & \multirow[b]{2}{*}{$\mathrm{P}$} \\
\hline & & Total & Actual & Theoretical & & \\
\hline $\mathrm{F}_{2}$ PI436626/Saratovskoe 6 & Blue/Brown & 589 & $547.0 / 42.0$ & $549.7 / 39.3$ & 0.07 & $0.90<\mathrm{P}<0.75$ \\
\hline$F_{2}$ PI346946/Pamyati Bersieva & Blue/Brown & 676 & $631.0 / 45.0$ & $630.9 / 45.1$ & 0.07 & $0.90<\mathrm{P}<0.75$ \\
\hline $\mathrm{F}_{3}$ PI346946/Pamyati Bersieva & Blue/Brown & 1983 & $1855 / 128$ & $1859 / 124$ & 0.06 & $0.90<\mathrm{P}<0.75$ \\
\hline
\end{tabular}




\section{Evaluation of hybrids by biochemical and molecular markers}

The amylose content in grain in $\mathrm{F}_{2}-\mathrm{F}_{3}$ individuals of PI346946/Pamyati Bersieva was estimated using biochemical analysis. And the results showed that amylose content in $\mathrm{F}_{2}$ hybrid populations ranged from $15 \%$ to $24 \%$, while in $\mathrm{F}_{3}$ hybrids from $11 \%$ to $22 \%$ (Figure 3), it was observed a decrease in the content of amylose with self-pollination.

From $\mathrm{F}_{2}$ generation, individuals K2-M10 and K2-M19 were distinguished with a relatively low content of amylose, namely $11.6 \%$ and $13.5 \%$. After analysis for amylose content, each panicle was analyzed visually according to their caryopsis shape as round character from the paternal shape and elongated character from the maternal shape. In spring, in the breeding nursery, the $\mathrm{F}_{3}-\mathrm{F}_{4}$ individuals from the population PI346946/Pamyati Bersieva were sown based on their shape in a separate plot, and their amylose content was estimated again after harvesting (Figure 4).

Among the studied samples, a sample was distinguished with a very low amylose content K1M4 with an elongated grain shape, as well as samples $\mathrm{K} 1 \mathrm{M} 3$ and $\mathrm{K} 1 \mathrm{M} 1$ with a round grain shape.

Subsequently, individuals of $\mathrm{F}_{3}-\mathrm{F}_{4}$ generation from PI346946/Pamyati Bersieva were analyzed by PCR using the $9 \mathrm{bF} / 15 \mathrm{delRB}$ marker to identify the $w x$ allele (Figure 5).

PCR analysis revealed that the most $\mathrm{F}_{3}-\mathrm{F}_{4}$ individuals were amylose type, three individuals of K1M1 (round), K1M3 (round) and K1M4 (elongated) with a product size of $108 \mathrm{bp}$, the glutinous forms of millet were identified. Thus, selected promising pre-breeding materials will be used for breeding Kazakhstan waxy proso millet varieties.

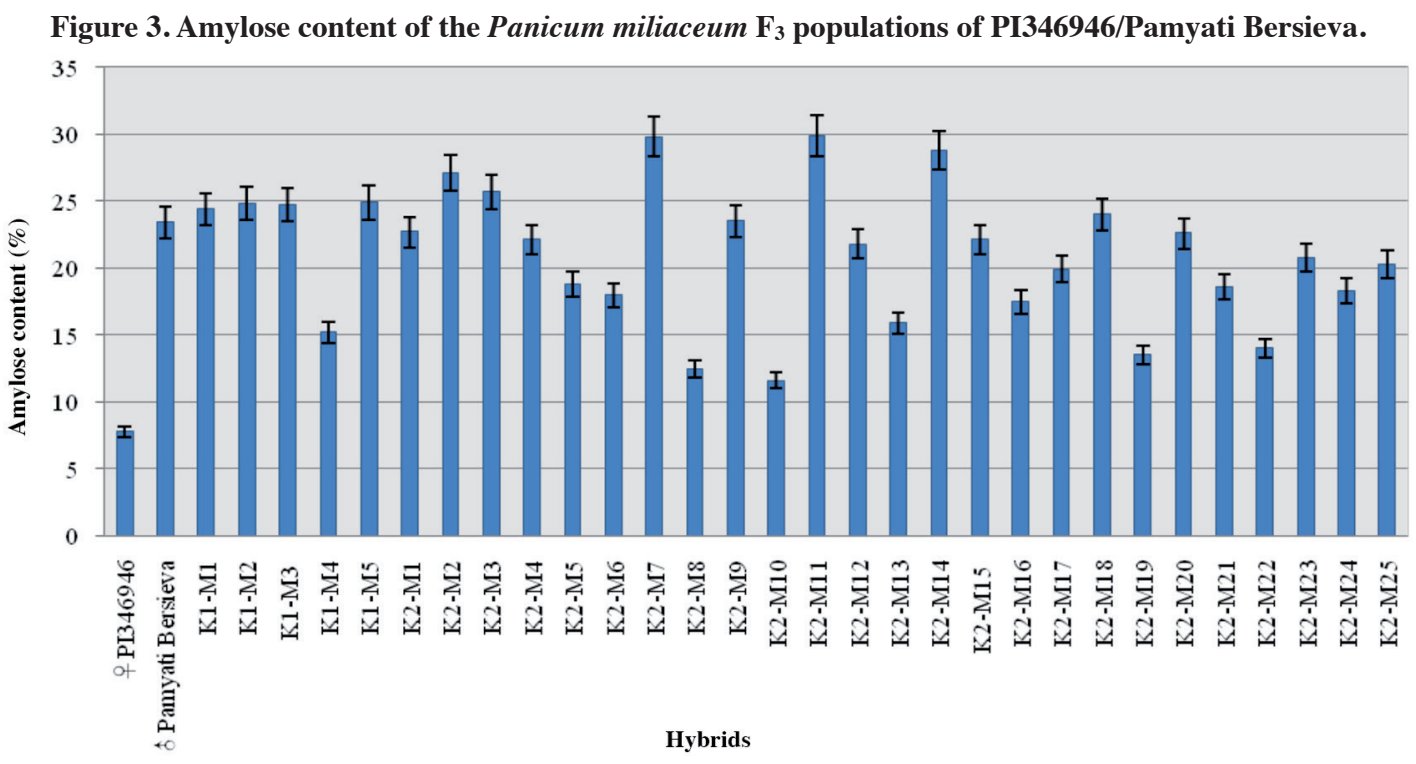

K1: Hybrids from $F_{2}$ PI346946/Pamyati Bersieva; K2: hybrids from $F_{3}$ PI346946/Pamyati Bersieva; M1, M2, M3: $1,2,3$ panicles.

Figure 4. Amylose content in Panicum miliaceum hybrid populations of the combination PI346946/Pamyati Bersieva F $_{4}$ generations.

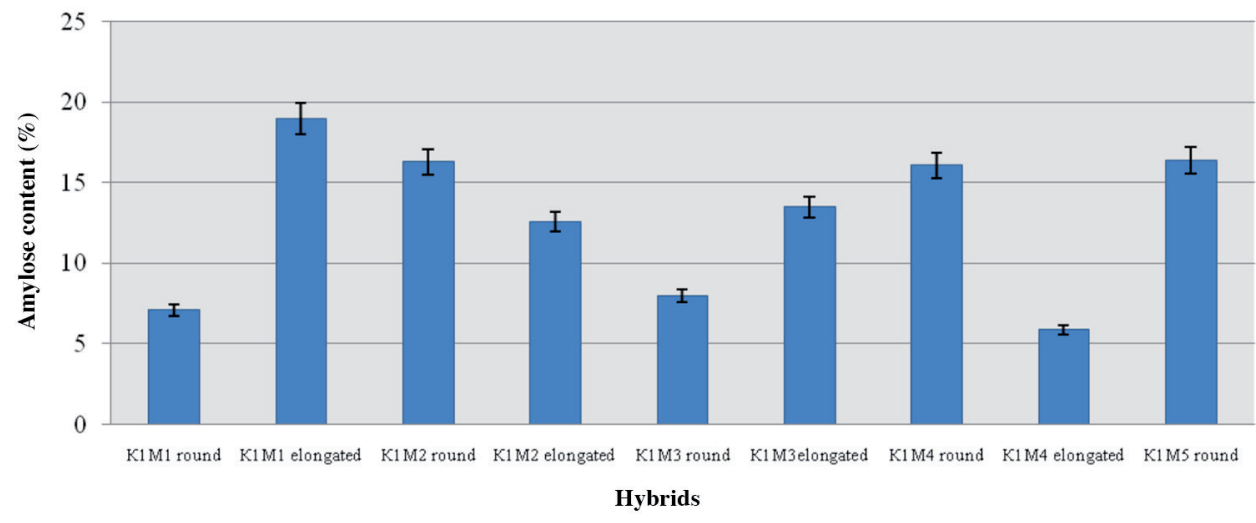


Figure 5. Detection of the waxy loci in the Panicum miliaceum $\mathrm{F}_{3}-\mathrm{F}_{4}$ individuals from PI346946/Pamyati Bersieva using the $9 \mathrm{bF} / 15 d e l R B$ marker.

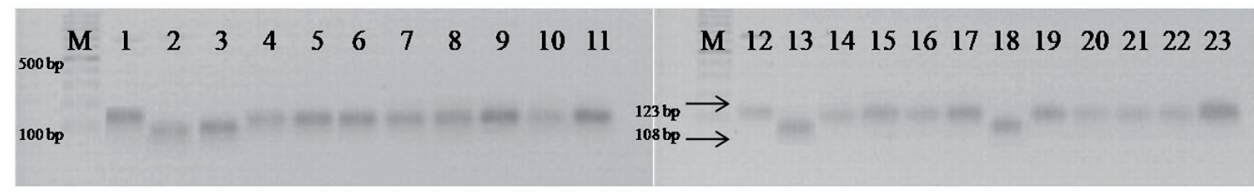

M: Marker; 1: Pamyati Bersieva; 2: PI346946; 3: K1M1 (round); 4: K1M1 (elongated); 5-8: K1M2 (round); 9-12: K1M2 (elongated); $13:$ K1M3 (round); 14, 15: K1M3 (elongated); 16, 17: K1M3 (round); 18: K1M4 (elongated); 19-23: K1M5 (round).

\section{DISCUSSION}

Amylose content is the most important biochemical indicator of grain quality. In high-amylose proso millet, the amylose content ranges from 20\% to 32\% (Beleia et al., 1980; Kim et al., 2012), while in low-amylose millet, amylose content is 3.3\%-11.4\% (Hoover et al., 1996; Kim et al., 2009). In the study carried out to create pre-breeding resources of waxy proso millet for breeding new Kazakhstan varieties, we focused on the assessment of amylose content in the grains of the initial breeding material. Among our materials, all varieties cultivated in Kazakhstan had an apparent intermediate and high-amylose content, and ranged from $14.6 \%$ to $29.3 \%$.

The amylose content in the waxy endosperm of millet is up to $3.5 \%$ and is controlled by the recessive alleles $w x-1 / w x$ 2 , and in the non-waxy endosperm by the dominant alleles $W x-1$ and $W x-2$ (Graybosch and Baltensperger, 2009). So far, the waxy gene of proso millet varieties cultivated in Kazakhstan has been never studied using marker-assisted selection. PCR analysis with 9bF/15delRB marker for identification of Waxy alleles confirmed that all Kazakhstan varieties included in the State Register are amylose type, which justifies the necessity of its breeding for introducing the wx loci.

Studies by a number of local scientists have shown that the content of amylose is a trait of polygenic nature and is stabilized only in $\mathrm{F}_{6}-\mathrm{F}_{7}$ generations in rice. When analyzing the samples obtained from PI346946/Pamyati Bersieva, it was found that the amylose content of $\mathrm{F}_{2}$ generations varies within $15 \%-24 \%$, in $\mathrm{F}_{3}$ generations $11 \%-22 \%$, in $\mathrm{F}_{4}$ generations 5.9\%-19.0\% (Figure 6), which suggest that there was a tendency towards a decrease in amylose a long with the generation after selection.

Regarding the breeding strategy, to avoid the genetic unification of the assortment genetic sources previously uninvolved in crossing are required for hybridization work on creation of waxy forms of millet. Glutinous samples of proso millet from the world collection PI346946, PI436626 ('Lung Shu 18'), PI436625 ('Lung Shu 16') are a valuable genetic source for creation of the first national glutinous millet variety with a complex of economically valuable traits by transferring the waxy gene to local varieties. Involvement of these genotypes in breeding research will further contribute not only to a decrease in the content of amylose in grain, but also to an increase in the yield and adaptive potential of millet in Kazakhstan due to the expansion of the genetic basis of the crop.

Figure 6. Variations in amylose content in the Panicum miliaceum populations of different generations.

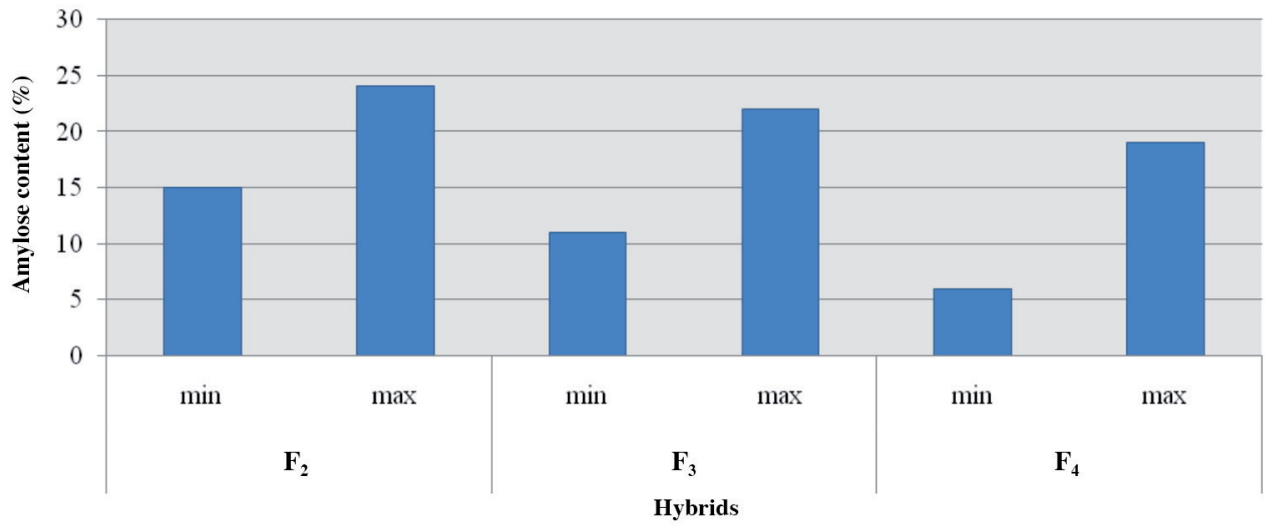




\section{CONCLUSIONS}

Biochemical screening for quantifying the amylose content in the grain of millet samples and marker analysis for choosing the right parents are intended to create glutinous millet variety with a complex of economically valuable traits. The glutinous samples introduced were crossed with Kazakhstan varieties, assisted by phenotyping by staining and genotyping by marker analysis, low-amylose pre-breeding materials were obtained.

In this work, the KI staining method was used to determine the grains of waxy type proso millet. A dominant $W x$ gene produced grain with endosperm starch that stained blue-black with iodine, while a recessive $w x$ gene produced grain with starch granules that stained red-brown. This method will be useful in phenotyping of much more germplasms to identify waxy type proso millet. Staining the endosperm on the $\mathrm{F}_{2}-\mathrm{F}_{3}$ generation with $2 \% \mathrm{KI}$ solution showed that stained caryopses ratio with blue and brown colors was close to 15:1; suggesting that two genes control wax traits. As a result of the PCR analysis, polymorphism with 15-bp deletion was observed in three individuals of K1M1 (round), K1M3 (round) and K1M4 (elongated) hybrids in the region of Intron 9/Exon10 in the S gene.

\section{REFERENCES}

Araki, M., Numaoka, A., Kawase, M., and Fukunaga, K. 2012. Origin of waxy common millet, Panicum miliaceum L. in Japan. Genetic Resources and Crop Evolution 59:1303-1308. https://doi.org/10.1007/s10722-011-9755-9.

Baltensperger, D.D. 2002. Progress with proso, pearl and other millets. p. 100-103. In Janick, J., and Whipkey, A. (eds.) Trends in new crops and new uses. ASHS Press, Alexandria, Virginia, USA.

Beleia, A., Varriano-Marston, E., and Hoseney, R. 1980. Characterization of starch from pearl millets. Cereal Chemistry 57:300-303.

Brink, M., and Belay, G. (eds.) 2006. Plant resources of tropical Africa 1. Cereals and pulses. PROTA Foundation, Wageningen, Netherlands/Backhuys Publishers, Leiden, Netherlands/CTA, Wageningen, Netherlands.

Dikshit, N., and Sivaraj, N. 2013. Diversity for protein and morpho-agronomical characteristics in proso millet germplasm collections of Ratnagiri District, Maharashtra, India. Vegetos 26:164-170.

Dzyuba, V.A., Esaulova, L.V., and Chukhir, I.N. 2015. Manifestation of Waxy endosperm genes in grain of rice varieties and hybrids. Grain Economy of Russia 1:3-12 (In Russian).

Fukunaga, K., Kawase, M., and Kato, K. 2002. Structural variation in the Waxy gene and differentiation in foxtail millet [Setaria italica (L.) P. Beauv.]: implications for multiple origins of the waxy phenotype. Molecular Genetics and Genomics 268(2):214-222.

Graybosch, R.A., and Baltensperger, D.D. 2009. Evaluation of the waxy endosperm trait in proso millet (Panicum miliaceum L.) Plant Breeding 128:70-73.

Hixon, R.M., and Brimhall, R. 1968. Waxy cereals and red iodine starches. p. 247-281. In Radley, J.A. (ed.) Starch and its derivatives. $4^{\text {th }}$ ed. Chapman and Hall, London, UK.

Hoover, R., Swamidas, G., Kok, L., and Vasanthan, T. 1996. Composition and physicochemical properties of starch from pearl millet grains. Food Chemistry 56:355-367.

Hunt, H.V., Denyer, K., Packman, L.C., Jones, M.K., and Howe, C.J. 2010. Molecular basis of the waxy endosperm starch phenotype in broomcorn millet. Molecular Biology and Evolution 27:1478-1494.

Hunt, H.V., Moots, H.M., Graybosch, R.A., Jones, H., Parker, M., Romanova, O., et al. 2013. Waxy phenotype evolution in the allotetraploid cereal broomcorn millet: Mutations at the GBSSI locus in their functional and phylogenetic context. Molecular Biology and Evolution 30(1):109-122.

Kim, S.K., Choi, H.J., Kang, D.K., and Kim, H.Y. 2012. Starch properties of native proso millet (Panicum miliaceum L.) Agronomy Research 10(1-2):311-318.

Kim, S., Sohn, E., and Lee, I. 2009. Starch properties of native foxtail millet, Setaria italica Beauv. Journal of Crop Science and Biotechnology 12:59-62.

Kimata, M., and Negishi, M. 2002. Geographical distribution of proso millet, Panicum miliaceum L. on iodostarch and phenol reactions; with special references to a northern propagation route into Japanese Islands. Environmental Education Studies, Tokyo Gakugei University 12:15-22.

Lu, H., Zhang, J., Liu, K.B., Wu, N., Li, Y., Zhou, K., et al. 2009. Earliest domestication of common millet (Panicum miliaceum) in East Asia extended to 10,000 years ago. Proceedings of the National Academy of Sciences of the United States of America 106(18):7367-7372.

Minina, E.L. 2014. A brief overview of the system of seed production and plant breeding, their legal regulation in the Russian Federation - M.: RGAU-Timiryazev K.A. Moscow Agricultural Academy, 64. Russian State Agrarian University - Moscow Timiryazev Agricultural Academy, Moscow, Russia (in Russian). 
Murray, M.G., and Thompson W.F. 1980. Rapid isolation of high molecular weight plant DNA. Nucleic Acids Research 8:4321-4325.

Sakamoto, S. 1987. Origin and dispersal of common millet and foxtail millet. Japan Agricultural Research Quarterly 21:84-89.

Santra, D.K., and Rose, D. 2013. Alternative uses of proso millet. NebGuide, G2218, p. 3-6. University of Nebraska-Lincoln Extension, Institute of Agriculture and Natural Resources, Lincoln, Nebraska, USA.

Sidorenko, V.S., Bobkov, S.V., Kotlyar, A.I., Gurinovich, S.O., and Starikova, Z.V. 2012. The area of seed millet in Russia. Agriculture 5:9-12 (in Russian).

Singh, M., and Adedeji, A.A. 2016. Physicochemical, pasting and thermal properties of acid and hydrothermal modified proso millet starch. ASABE paper $N^{\circ} 2460194$. American Society of Agricultural and Biological Engineers (ASABE), St. Joseph, Michigan, USA. doi:10.13031/aim.202460194.

Tsygankov, I.G., Tsygankov, V.I., Tsygankova, M., and Yu, M. 2004. Millet in the dry steppe zone of Western Kazakhstan. Agricultural Sciences 2:91-95 (in Russian).

Zhang, D-Z., Panhwar, R.B., Liu, J.-J., Gong, X.-W., Liang, J.-B., Liu, M., et al. 2019. Morphological diversity and correlation analysis of phenotypes and quality traits of proso millet (Panicum miliaceum L.) core collections. Journal of Integrative Agriculture 18(5):958-969.

Zotikov, V.I., Sidorenko, V.S., Bobkov, S.V., Kotlyar, A.I., and Gurinovich, S.O. 2012. Area and production of proso millet (Panicum miliaceum L.) in Russia. p. 3-9. In Advances in broomcorn millet research. Proceedings of the $1^{\text {st }}$ International Symposium on Broomcorn Millet. Northwest A\&F University Press (NWSUAF), Yangling, Shaanxi, China. 